\title{
Reductions in Hydrogen Sulfide Precede Onset of Mitochondrial Quality Control in the Corneal Kindled Mouse Model of Epilepsy
}

\author{
Christi Cho ${ }^{1}$, Maxwell Zeigler ${ }^{1}$, Stephanie Mizuno ${ }^{2}$, Richard S. Morrison ${ }^{3}$, Rheem Totah ${ }^{1}$, and Melissa Barker- \\ Haliski ${ }^{2, *}$
}

1 Department of Medicinal Chemistry, University of Washington, Seattle, WA USA

2 Department of Pharmacy, University of Washington, Seattle, WA USA

3 Department of Neurology, University of Washington, Seattle, WA USA

* Correspondence: mhaliski@uw.edu; Tel.: (1-206-685-1783)

\begin{abstract}
Epilepsy is a heterogenous neurological disorder characterized by recurrent unprovoked seizures, mitochondrial stress, and neurodegeneration. Hydrogen sulfide $\left(\mathrm{H}_{2} \mathrm{~S}\right)$, a gasotransmitter, promotes mitochondrial function and biogenesis, elicits neuromodulation and neuroprotection, and may acutely suppress seizures. A major gap in knowledge remains in understanding the role of mitochondrial dysfunction and progressive changes in $\mathrm{H}_{2} \mathrm{~S}$ levels following acute seizures and during epileptogenesis. We thus sought to quantify changes in $\mathrm{H}_{2} \mathrm{~S}$ and its methylated metabolite (MeSH) via LC-MS/MS subsequent to acute maximal electroshock and $6 \mathrm{~Hz} 44 \mathrm{~mA}$ seizures in mice, as well as in the corneal kindled mouse model of chronic seizures. Plasma $\mathrm{H}_{2} \mathrm{~S}$ was acutely reduced after a maximal electroshock seizure. $\mathrm{H}_{2} \mathrm{~S}$ or MeSH levels in whole brain homogenate and expression of related genes in corneal kindled mice were not altered. However, plasma $\mathrm{H}_{2} \mathrm{~S}$ and $\mathrm{MeSH}$ levels were significantly lower during kindling, but not after established kindling. Morever, we demonstrated a time-dependent increase in expression of mitochondrial membrane integrity-related proteins, Opa1, Mfn2, Drp1, and Mff during kindling, which did not correlate with gene expression. Taken together, short-term reductions in plasma $\mathrm{H}_{2} \mathrm{~S}$ could be a novel biomarker for seizures. Future studies should further define the role of $\mathrm{H}_{2} \mathrm{~S}$ and mitochondrial stress in epilepsy.
\end{abstract}

Keywords: epilepsy; hydrogen sulfide; corneal kindled mice, mitochondrial dysfunction, oxidative stress, LC-MS/MS; temporal lobe epilepsy; neurological disorder; gasotransmitter 


\section{Introduction}

Mitochondria are the predominant source of reactive oxygen species underlying oxidative neuronal damage, including in the brains of patients with acquired epilepsy [1]. Oxidative stress and mitochondrial dysfunction can directly induce apoptosis or necrosis; this aberrant neuronal loss can then increase seizure susceptibility [2]. One mechanism through which the oxidative damage can be mitigated is through the scavenging of reactive oxygen and reactive nitrogen species by the endogenous gasotransmitter, hydrogen sulfide $\left(\mathrm{H}_{2} \mathrm{~S}\right)$. Hydrogen sulfide is an important signaling molecule involved in various biological processes including cytoprotection, anti-inflammation, oxygen sensing, neuromodulation and neuroprotection [3-6]. The antioxidant function of $\mathrm{H}_{2} \mathrm{~S}$ has been extensively studied. For example, $\mathrm{H}_{2} \mathrm{~S}$ can mitigate oxidative damage through an increase in intracellular glutathione levels by modulating the activity of the cystine transporter system $[7,8] . \mathrm{H}_{2} \mathrm{~S}$ can also alter the activity of key antioxidant enzymes including glutathione peroxidase, superoxide dismutase, and catalase to attenuate oxidative stress [9]. Additionally, $\mathrm{H}_{2} \mathrm{~S}$ is capable of indirectly upregulating the expression of several antiapoptotic transcription factors and mitochondrial biogenesis genes to promote cell survival [10]. In mammalian tissue, $\mathrm{H}_{2} \mathrm{~S}$ is mainly synthesized via cystathionine $\beta$ synthase (CBS), cystathionine $\gamma$-lyase (CSE or CTH), and 3-mercaptopyruvate sulfurtransferase (3-MST or MPST) [10-14]. CBS and 3-MST are a major source of $\mathrm{H}_{2} \mathrm{~S}$ production in the brain [15-17]. 3-MST is localized in the cytosol and mitochondria, while CBS and CSE are localized in the cytosol, but have been shown to translocate to the mitochondria under stress conditions [18]. Non-enzymatic production of $\mathrm{H}_{2} \mathrm{~S}$ requiring a cysteine donor, iron, and vitamin B6 is also a contributor to endogenous $\mathrm{H}_{2} \mathrm{~S}$ levels in red blood cells, and potentially the brain [19].

Disruptions in mitochondrial membrane integrity dynamics and synaptic dysfunction are both associated with, and causally related to, epilepsy. While disturbances in energy metabolism and ATP production have received significant attention in the pathogenesis of epilepsy [20,21], abnormalities in mitochondrial shape, size, and distribution can also influence neurological disease [22]. The molecular regulators of mitochondrial membrane integrity dynamics, including fusion and fission (i.e., fragmentation), may possess important roles in neuronal survival [22,23]. Excessive fission is frequently reported in various neurological diseases, including in rodent epilepsy models [24]. The well-conserved dynamin-related GTPases, including dynaminrelated protein 1 (Drp1), promote fission in conjunction with mitochondrial fission factor (Mff), one of at least two mitochondrial proteins involved in recruitment of Drp1 from the cytosol to the outer mitochondrial membrane. Endophilin B1 (Endo-B1) activates stressresponse proteins (e.g. Bax), to promote cytochrome $c$ release and apoptosis [25], and Endo-B1 has been shown to be neuroprotective in other neurological disease models $[26,27]$. The neuron-specific isoform, Endo-B1-B/C participates in the trafficking of the TrkA receptor, promoting receptor internalization and recycling in early endosomes and preventing endosome-lysosome fusion [28]. Further, histone deacetylase 2 (HDAC2) regulates the expression of Endo-B1, particularly neuron-specific isoforms B/C [26,27], and is thus a non-mitochondrial marker of mitochondrial function that may prevent to neuronal pathology [29]. However, how these molecular regulators are dynamically altered during the development of chronic seizures or epilepsy in various animal models has yet to be established. Furthermore, both Drp1 and Mff are also involved in synaptic vesicle recycling, interacting with clathrin to promote endosome formation [30], suggesting a role for mitochondrial fission proteins in the regulation of synaptic plasticity and network remodeling during the development of a hyperexcitable neuronal network, i.e. epilepsy.

The function of $\mathrm{H}_{2} \mathrm{~S}$ in preserving mitochondrial function and its effect on mitochondrial dynamics has been previously established. A 3-MST-mediated increase in $\mathrm{H}_{2} \mathrm{~S}$ levels attenuates mitochondrial damage in cerebral endothelial cells during oxygenglucose deprivation/reoxygenation injury [17]. Exogenous $\mathrm{H}_{2} \mathrm{~S}$ preserves mitochondrial function following myocardial ischemia reperfusion injury in mice by mitigating infarct 
size and promoting cell survival in a dose-dependent manner [31]. $\mathrm{H}_{2} \mathrm{~S}$ promotes mitochondrial fusion and inhibits fission by modulating genes involved in mitochondrial membrane integrity dynamics, including Drp1 and Mfn2 [32]. At higher concentrations, however, $\mathrm{H}_{2} \mathrm{~S}$ elicits cell toxicity by promoting apoptosis through the recruitment of Bax to the mitochondria. Further, elevated $\mathrm{H}_{2} \mathrm{~S}$ levels results in cerebellar mitochondrial swelling and a decrease in the mitochondrial membrane potential in rat models of ethylmalonic encephalopathy highlighting the biphasic nature of $\mathrm{H}_{2} \mathrm{~S}$ induced cellular protection and toxicity [10,33].

Despite clear understanding of the mechanisms underlying $\mathrm{H}_{2} \mathrm{~S}$ expression and its regulation of mitochondrial integrity dynamics, as well as the potential role of $\mathrm{H}_{2} \mathrm{~S}$ in neuropathological conditions, there is a major gap in understanding how $\mathrm{H}_{2} \mathrm{~S}$ levels fluctuate with the development of epilepsy. One of the major barriers to clearly defining the role of $\mathrm{H}_{2} \mathrm{~S}$ in the brain has been the prior inability to precisely measure $\mathrm{H}_{2} \mathrm{~S}$ concentrations in isolated tissues [34]. While prior reports have indirectly assessed the role of $\mathrm{H}_{2} \mathrm{~S}$ on cognitive function in rodents with chemically-kindled seizures [35], no study has yet quantified the progressive changes in $\mathrm{H}_{2} \mathrm{~S}$ levels in the brains during the kindling process itself. Further, little work has been conducted to establish how acute seizures influence $\mathrm{H}_{2} \mathrm{~S}$ levels in the brain and periphery (i.e. plasma). We thus sought to establish whether $\mathrm{H}_{2} \mathrm{~S}$ and downstream enzymatic metabolites were dynamically altered by acute or chronic seizures [36]. The acute seizure models (maximal electroshock (MES)) and $6 \mathrm{~Hz} 44 \mathrm{~mA}$ model were selected to assess changes in $\mathrm{H}_{2} \mathrm{~S}$ expression with a single evoked generalized tonic-clonic or focal seizure, respecitvely. Kindling effectively models epileptogenesis on a protracted timescale [37], allowing for the evaluation of changes in neuropathology or gene expression with tight control of timing between neurological insults. Therefore, the chronic $60 \mathrm{~Hz}$ corneal kindling model was selected to assess disease-related changes in $\mathrm{H}_{2} \mathrm{~S}$ expression. Lastly, we investigated evidence of dynamic changes in mitochondrial integrity-related protein expression during corneal kindling, which may provide clarify the role of neurodegeneration and oxidative damage on the onset of spontaneous seizures.

\section{Results}

2.1 Plasma $\mathrm{H}_{2} \mathrm{~S}$ Levels Are Reduced Following an Acutely Evoked Maximal Electroshock, but not $6 \mathrm{~Hz} 44 \mathrm{~mA}$, Seizure

To address whether a maximal electroshock (MES) generalized or $6 \mathrm{~Hz} 44 \mathrm{~mA}$ focal seizure also differentially altered $\mathrm{H}_{2} \mathrm{~S}$ and its methylated metabolite methyl sulfide $(\mathrm{MeSH})$ levels, we quantified the levels within the whole brain and plasma from mice collected 1 hour after transcorneal stimulation. No significant differences from shamstimulated mice were apparent between MES and $6 \mathrm{~Hz} 44 \mathrm{~mA}$ stimulated mice in the levels of $\mathrm{H}_{2} \mathrm{~S}$ (Figure $1 \mathrm{~A} ; \mathrm{F}_{(2,18)}=0.298, \mathrm{p}>0.7$ ) or MeSH (Figure $1 \mathrm{~B} ; \mathrm{F}_{(2,18)}=0.605, \mathrm{p}>0.5$ ) within the whole brain 1 hour after acute transcorneal stimulation. Conversely, plasma levels of $\mathrm{H}_{2} \mathrm{~S}$ were significantly reduced following an electrical seizure stimulation (Figure 1C; $\left.\mathrm{F}_{(2,21)}=3.518, \mathrm{p}=0.0481\right)$, with post-hoc Dunnett's tests demonstrating a significant reduction in $\mathrm{H}_{2} \mathrm{~S}$ levels only in MES-stimulated mice $(\mathrm{p}=0.0280)$. However, no such significant differences were observed in the plasma levels of $\mathrm{MeSH}$ following electrical seizure stimulation (Figure 1D; $\mathrm{F}_{(2,21)}=1.808, \mathrm{p}>0.1$ ). Follow up studies are needed to determine if the short-term reductions in plasma $\mathrm{H}_{2} \mathrm{~S}$ levels, but not MeSH levels, may be a reliable biomarker of an acute generalized tonic-clonic seizure. 
A

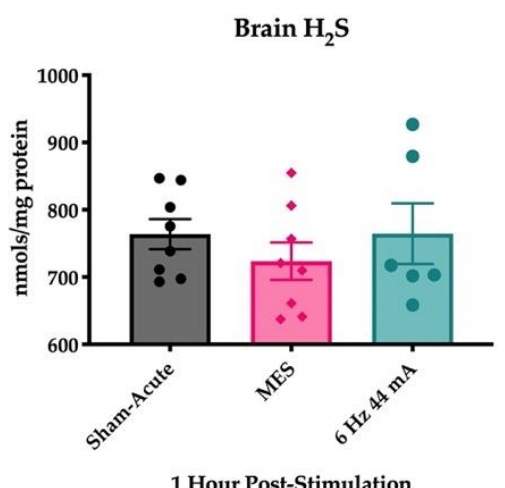

C

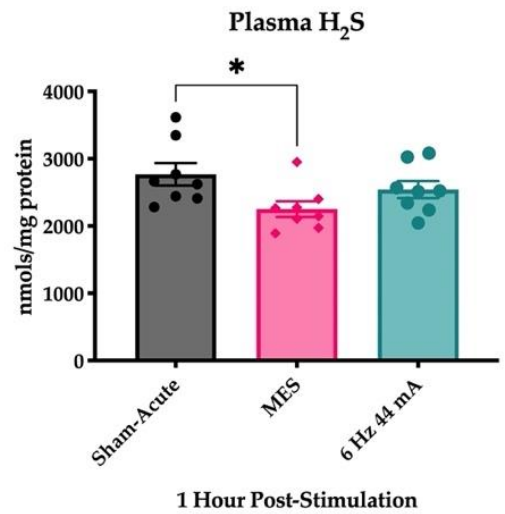

B

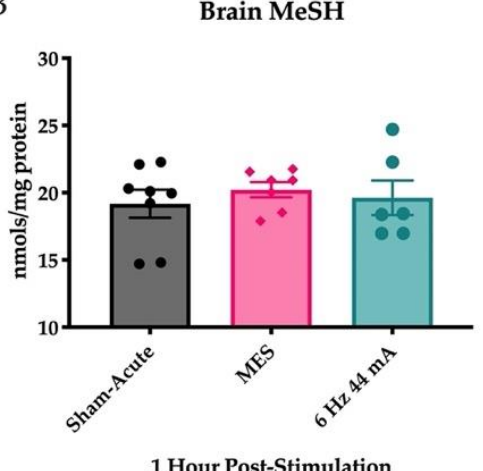

D

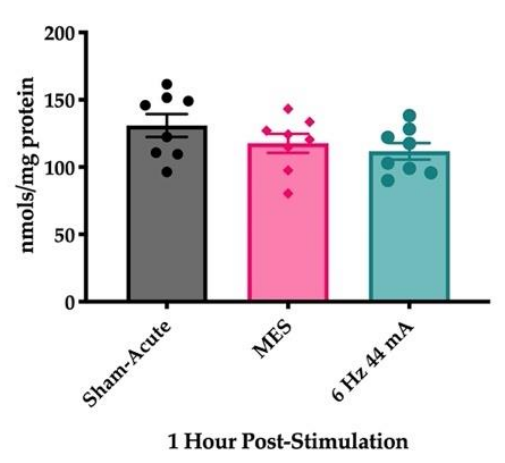

Figure 1. Acutely evoked seizures do not lead to significant changes in $\mathrm{H}_{2} \mathrm{~S}$ levels in isolated whole brain tissues 1 hour following electrical stimulation of male CF- 1 mice $(n=8$ mice/stimulation group). A) The levels of $\mathrm{H}_{2} \mathrm{~S}$ are not grossly altered in isolated whole mouse brain 1 hour after transcorneal stimulation to induce either a MES generalized tonic-clonic seizure or $6 \mathrm{~Hz} 44 \mathrm{~mA}$ focal seizure. B) The levels of MeSH are not grossly altered in isolated whole mouse brains 1 hour after transcorneal stimulation to induce either a MES generalized tonic-clonic seizure or $6 \mathrm{~Hz} 44 \mathrm{~mA}$ focal seizure. C) The levels of $\mathrm{H}_{2} \mathrm{~S}$ are significantly reduced in purified plasma collected 1 hour after transcorneal stimulation with a MES generalized tonic-clonic seizure. There is no significant reduction in $\mathrm{H}_{2} \mathrm{~S}$ levels in the plasma of mice that received a $6 \mathrm{~Hz} 44 \mathrm{~mA}$ focal seizure stimulation. ${ }^{*}$ indicates significantly different from sham-stimulated mice, $p<0.05$. D) The levels of MeSH are not grossly altered in the plasma of mice collected 1 hour after transcorneal stimulation to induce either a MES generalized tonic-clonic seizure or $6 \mathrm{~Hz} 44 \mathrm{~mA}$ focal seizure.

\subsection{Corneal kindling acquisition in wild type experimental mice.}

Male CF-1 mice were divided into three stimulation groups that underwent the corneal kindling procedure, and a sham-kindled cohort. There was no significant difference in the development of the fully kindled state in mice that were euthanized 1 day or 7 days postkindling (Figure 2); mice that were euthanized after 5 corneal stimulations (i.e. on the 3rd experimental day) also tracked alongside the two kindling groups until the time of euthanasia. The $5^{\text {th }}$ stimulation was selected as a time point that preceeds the onset of secondarily generalized focal seizures [38]. There was no significant difference in the percent of fully kindled mice in both kindling groups; both groups attained $100 \%$ of animals fully kindled by 26 stimulations (Figure 2B). Further, the number of stimulations needed to attain fully kindled status was no different between the mice that were euthanized 1 day or 7 days post-kindling (Figure 2C). 

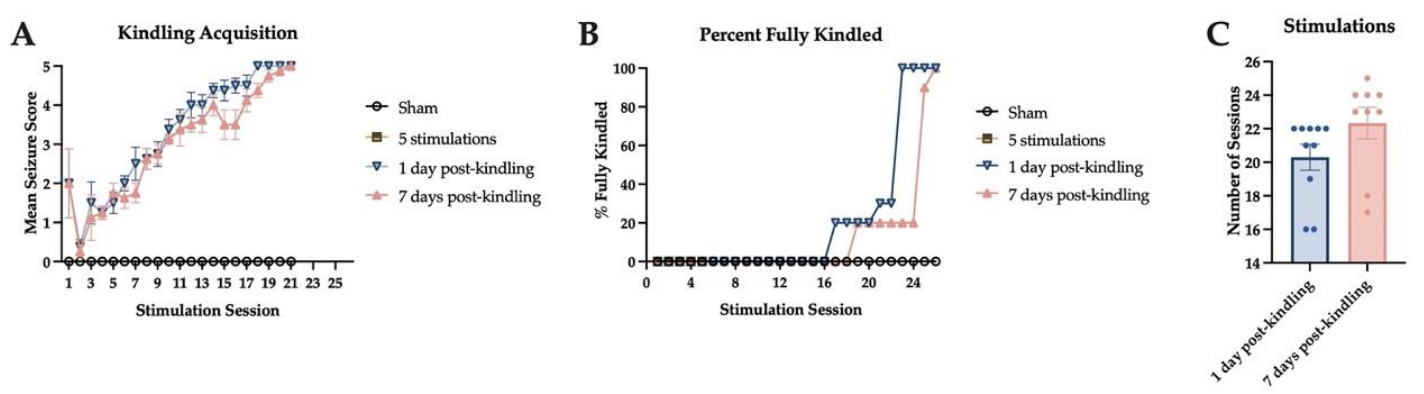

Figure 2. The acquisition of the fully kindled state was no different between the experimental groups used for assessment of $\mathrm{H}_{2} \mathrm{~S}$ levels in isolated mouse brains during or after the corneal kindling procedure. Male CF-1 mice were electrically kindled twice daily with a $3.0 \mathrm{~mA} 60 \mathrm{~Hz}$ electrical stimulus delivered bilaterally to anesthetized corneas; sham kindled mice were similarly handled but no stimulation was delivered. A) The mean seizure score of mice that were euthanized 1 day after attaining the fully kindled state was not different from mice that were euthanized 7 days after reaching the kindling criterion. B) The percent of fully kindled mice in each cohort was not significantly different. C) There was no significant difference between the two fully kindled cohorts in the numbers of kindling sessions needed to reach kindling criterion.

2.3 The Corneal Kindling Process Does Not Significantly Impact $\mathrm{H}_{2}$ S-related Gene Expression $\mathrm{H}_{2} \mathrm{~S}$ undergoes methylation via methyl transferase like protein $7 \mathrm{~B}$, and our group has previously identified several mouse orthologs (Mett17a1, Mettl7a2, and Mettl7a3) for this study [39]. These primary genes associated with $\mathrm{H}_{2} \mathrm{~S}$ synthesis and metabolism were quantified during kindling progression (Figure 3). Slight alterations in gene expression of three Mettl7a isoforms were observed across the different treatment groups compared to the sham kindling group (Figure 3A-C); however, the changes were not significant. Similarly, Cbs and Mpst expression altered slightly across the different treatment groups but was not significantly different from sham-kindled mice (Figure 3D-E). Finally, the expression of Txnrd1 was significantly impacted by the corneal kindling process (Figure $3 \mathrm{G} ; \mathrm{F}_{(3,33)}=2.917$, $\left.\mathrm{p}=0.0486\right)$, albeit there were no post-hoc differences between experimental groups and sham-kindled animals.
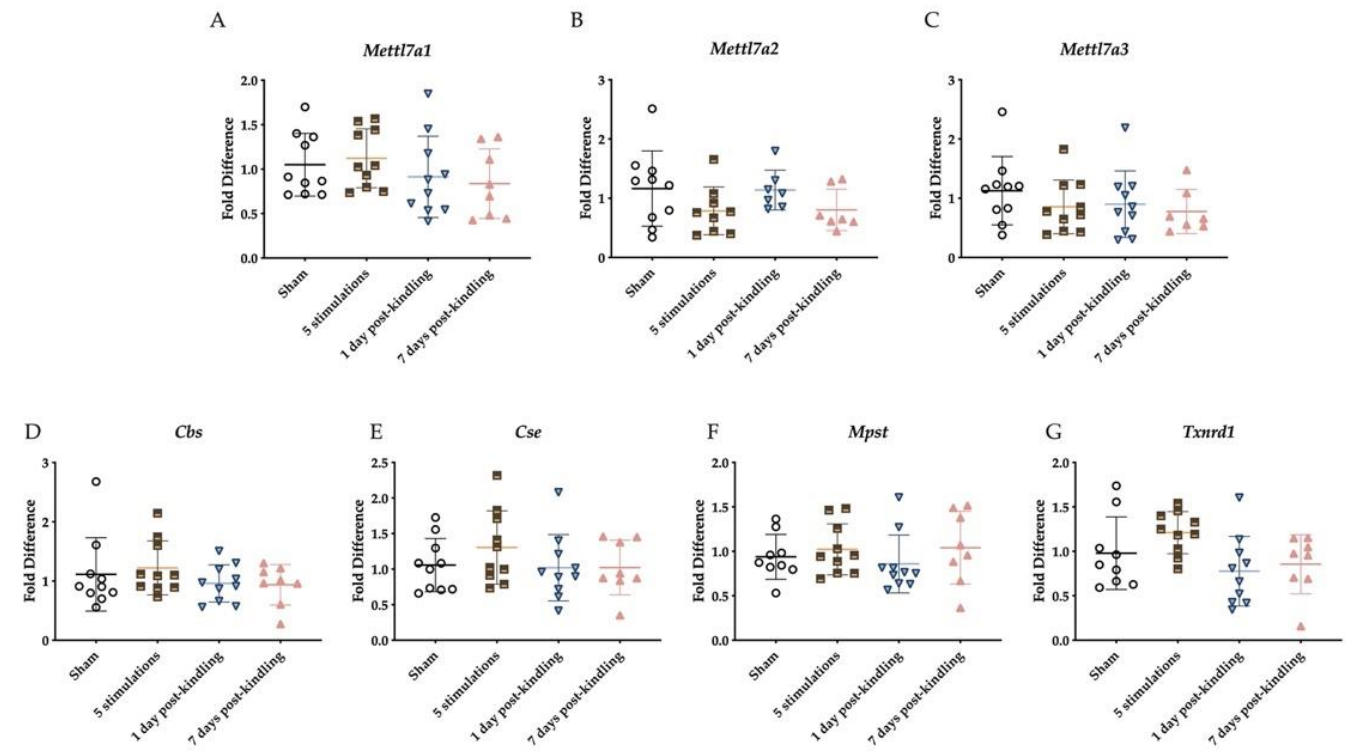

Figure 3. RT-qPCR analysis of genes related to $\mathrm{H}_{2} \mathrm{~S}$ production and metabolism. No significant changes in expression were observed in genes related to $\mathrm{H}_{2} \mathrm{~S}$ metabolism, including the Mettl7a isoforms. The expression of Txnrd1 was significantly altered upon acquisition of the kindled state while no significant changes were observed in Cbs, Cth, and Mpst upon full acquisition of the kindled state. 
2.4 Repeated Corneal Stimulation Leads to Transient Reductions in $\mathrm{H}_{2} \mathrm{~S}$ and MeSH Levels in Plasma and Brain

To determine whether $\mathrm{H}_{2} \mathrm{~S}$ and MeSH levels were only acutely or chronically impacted by the corneal kindling procedure, we next quantified the levels in both plasma and whole brain homogenates after 5 stimulations, 1 day post-kindling, or 7 days post-kindling. Levels of $\mathrm{H}_{2} \mathrm{~S}$ in the brains of mice at these three experimental conditions were not significantly altered with time in the kindling process (Figure 4A; $\left.\mathrm{F}_{(3,35)}=0.8471, \mathrm{p}>0.4\right)$. Brain MeSH levels were also not significantly different between experimental groups and sham-kindled mice, albeit there was a strong trend for a main effect of stimulation (Figure $4 \mathrm{~B} ; \mathrm{F}_{(3,35)}=2.683$, $\mathrm{p}=0.0617$ ). However, consistent with the acute seizure induction models studies (section 2.1), there was a strong and significant main effect of seizure stimulation on plasma $\mathrm{H}_{2} \mathrm{~S}$ levels (Figure $4 \mathrm{C} ; \mathrm{F}_{(3,35)}=29.13$, $\mathrm{p}<0.0001$ ), with post-hoc tests revealing significant reductions in plasma $\mathrm{H}_{2} \mathrm{~S}$ levels following the fifth transcorneal stimulation $(p=0.0015)$. Interestingly, there was also a significant reduction in plasma MeSH levels in the stimulated cohorts (Figure 4D; $\left.\mathrm{F}_{(3,35)}=5.048, \mathrm{p}=0.0055\right)$, with post-hoc tests revealing a robust reduction in plasma $\mathrm{MeSH}$ levels following the fifth transcorneal stimulation. Thus, plasma $\mathrm{H}_{2} \mathrm{~S}$ levels are consistently and significantly reduced following a seizure acutely evoked by a $60 \mathrm{~Hz}$, but not $6 \mathrm{~Hz}$, corneal stimulation, as both the MES and $60 \mathrm{~Hz}$ corneal kindled mouse models exhibited robust reductions in plasma $\mathrm{H}_{2} \mathrm{~S}$ levels 1 hour following stimulation.


Figure 4. The levels of $\mathrm{H}_{2} \mathrm{~S}$ and $\mathrm{MeSH}$ are quantified with development of the corneal kindled mouse model of temporal lobe epilepsy. A) Changes in brain $\mathrm{H}_{2} \mathrm{~S}$ levels are not significantly affected by $60 \mathrm{~Hz}$ transcorneal stimulation needed to induce the fully kindled state. B) The levels of MeSH in the brain are significantly reduced in mice euthanized 1 hour after the 5 th transcorneal stimulation, but levels are no different from sham-kindled mice when assessed 1 day or 7 days postkindling. C) The levels of $\mathrm{H}_{2} \mathrm{~S}$ in purified plasma are significantly reduced in mice euthanized 1 hour after the 5 th transcorneal stimulation, but levels are no different from sham-kindled mice when assessed 1 day or 7 days post-kindling. D) The levels of MeSH in the plasma are significantly reduced in mice euthanized 1 hour after the 5 th transcorneal stimulation. However, levels of MeSH 
are no different from sham-kindled mice when assessed 1 day and 7 days after the acquisition of the fully kindled state

The levels of thiocyanate and reduced glutathione (GSH) were similarly assessed during the kindling process to determine whether $\mathrm{H}_{2} \mathrm{~S}$ metabolism and overall tissue redox status were also affected by corneal kindling (Figure 5). Thiocyanate is a detoxification product of cyanide via $\mathrm{H}_{2} \mathrm{~S}$ and the transsulfuration pathway catalyzed mainly by 3-MST and rhodanese [40]. Following corneal stimulation, thiocyanate levels were reduced in the brains of mice (Figure $5 \mathrm{~A} ; \mathrm{F}_{(3,32)}=2.90, \mathrm{p}=0.050$ ), and post-hoc tests revealed that this decrease attained significance after the the 5 th corneal stimulation $(\mathrm{p}=0.0312)$, further demonstrating that acute seizure history affects brain $\mathrm{H}_{2} \mathrm{~S}$

biosynthesis and metabolism. However, whole brain GSH levels were not significantly impacted by the kindling process (Figure $5 \mathrm{~B} ; \mathrm{F}_{(3,35)}=1.026, \mathrm{p}>0.3$ ), suggesting that redox status changes were not associated with corneal kindling. Whether hippocampal GSH levels would have been affected remains to be further determined. Within purified plasma, there was a significant effect of seizure history on thiocyanate levels (Figure 5C; $\left.\mathrm{F}_{(3,33)}=25.76, \mathrm{p}<0.0001\right)$; post-hoc tests again revealed that the most significant reductions in thiocyanate levels were detected after the 5 th stimulation $(\mathrm{p}<0.0001)$. Plasma GSH levels were also markedly reduced in mice that had a history of chronic seizures (Figure 5D; $\left.\mathrm{F}_{(3,33)}=5.276, \mathrm{p}=0.0044\right)$. Interestingly, levels of GSH in the plasma of mice were reduced following the 5 th corneal stimulation $(p=0.0324)$, as well as 1 day after attaining the fully kindled state $(p=0.0036)$, but there was no difference from sham for fully kindled mice 7 days post-kindling ( $p>0.8)$. Thus, brain and plasma thiocyanate levels, as well as plasma GSH concentrations are reduced with an acute history of repeated seizures.

A



C

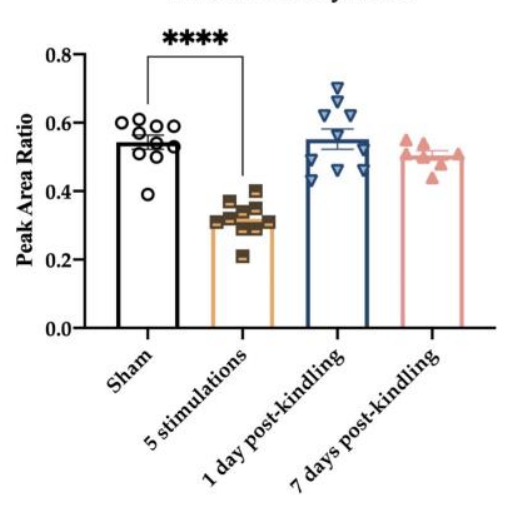

B

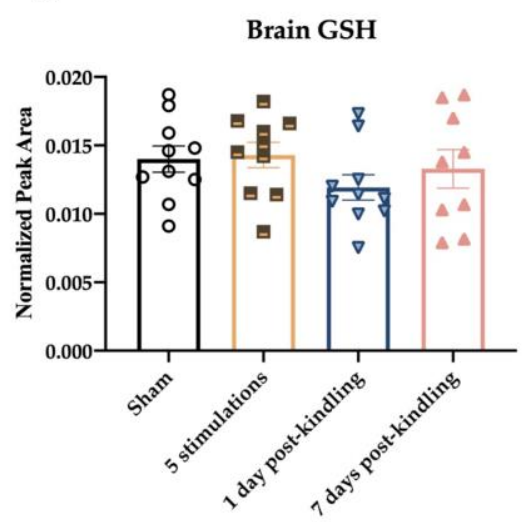

D Plasma GSH

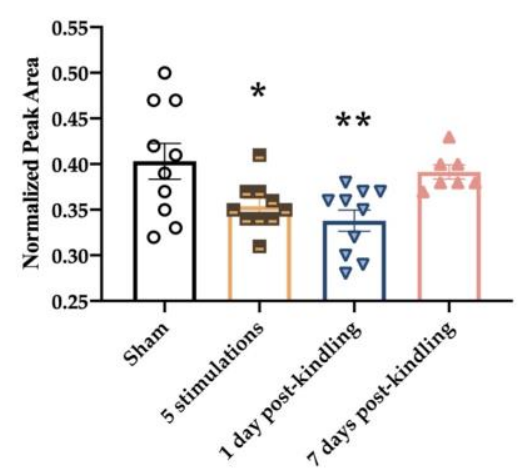

Figure 5. The levels of thiocyanate and reduced glutathione (GSH) were quantified with development of the corneal kindled mouse model of temporal lobe epilepsy. A) Changes in brain $\mathrm{H}_{2} \mathrm{~S}$ levels were significantly reduced 1 hour after $60 \mathrm{~Hz}$ transcorneal stimulation needed to induce 
the fully kindled state, but there is no difference from sham-kindled mice when assessed 1 day and 7 days post-kindling. B) The levels of GSH in the brain were not significantly different from sham-kindled mice when assessed after the 5th stimulation, 1 day, or 7 days post-kindling. C) The levels of thiocyanate in purified plasma were significantly reduced in mice euthanized 1 hour after the 5 th transcorneal stimulation, but levels are no different from sham-kindled mice when assessed 1 day or 7 days post-kindling. D) The levels of GSH in the plasma were significantly reduced in mice euthanized 1 hour after the 5 th transcorneal stimulation, as well as in mice euthanized 1 day after the acquisition of the fully kindled state. However, levels of GSH were no different from sham-kindled mice when assessed 7 days post-kindling.

\subsection{Corneal Kindling Attenuates Inner Mitochondrial Membrane-Associated Gene Expression} In addition to assessing the biosynthesis and metabolism of $\mathrm{H}_{2} \mathrm{~S}$ and general redox status, we quantified the expression of Nos2, which contributes to the generation of reactive nitrogen species and cysteine modification underlying mitochondrial signaling and neuroinflammation. There was a main effect of stimulation on Nos2 expression (Figure 6B; $\left.\mathrm{F}_{(3,31)}=3.195, \mathrm{p}=0.0370\right)$. Post-hoc tests demonstrated that the brain expression of Nos 2 was significantly elevated in mice subjected to five simulations of corneal kindling compared to the sham control group ( $\mathrm{p}=0.0162$ ), while Nos2 levels in the brain 1 or 7 days after the acquisition of the fully kindled state were no different from sham-kindled mice (Figure $6 \mathrm{~B} ; \mathrm{p}>0.8$ ). To further determine whether redox status and $\mathrm{H}_{2} \mathrm{~S}$ biosynthesis changes were also associated with changes in mitochondrial integrity dynamics, we quantified the expression of two genes critically involved in inner and outer mitochondrial membrane integrity dynamics, Opa1 and $M f n 2$, respectively. Opa1 gene expression was significantly decreased by the kindling stimulation (Figure 6C; $\mathrm{F}_{(3,34)}=4.850$, $\mathrm{p}=0.0065$ ), with post-hoc Dunnett's test demonstrating that these reductions were most measured after attaining the fully-kindled state ( 1 day post-kindling, $\mathrm{p}=0.0058 ; 7$ days post-kindling, $\mathrm{p}=0.0084$ ). Minor alterations in $M f n 2$ gene expression were observed across the different kindling groups, although the changes were not significant (Figure 6D).
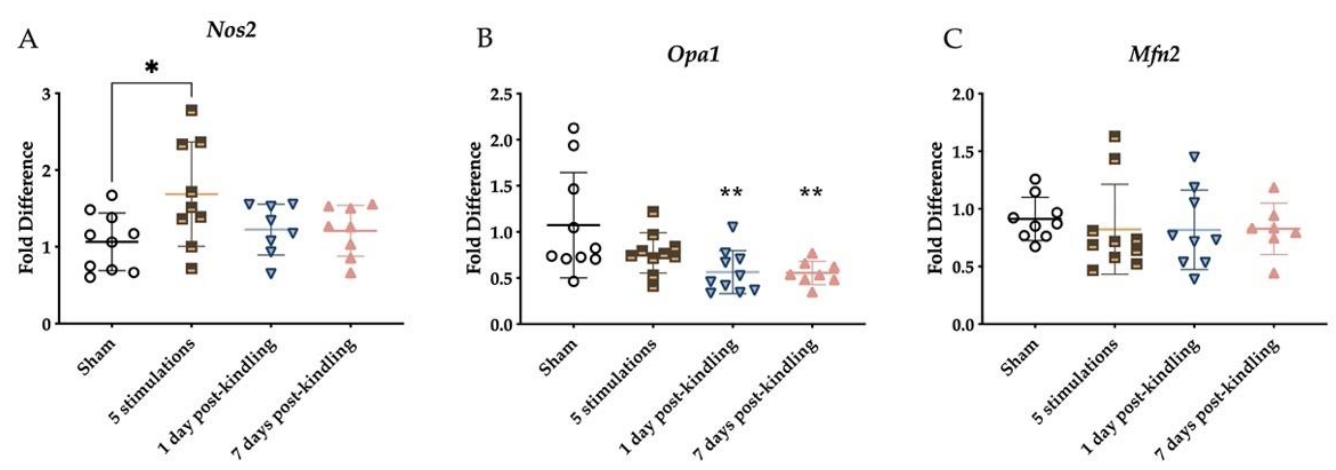

Figure 6. RT-qPCR analysis of genes related to mitochondrial stress normalized to the reference gene, Gusb. Nos2 was significantly upregulated after five stimulations of corneal kindling but not altered after the acquisition of the fully kindled state. Opa1 was significantly downregulated after full acquisition of the kindled state but minimally altered after five stimulations while kindling did not significantly alter the expression of $M f n 2$.

\subsection{Mitochondrial Integrity Dynamics Are Altered by Corneal Kindling}

An additional cohort of corneal kindled mice were then used to isolate whole hippocampus so as to assess the changes in the expression of mitochondrial membrane integrity dynamics-regulating proteins after establishment of the fully kindled state versus baseline levels. Mitochondrial proteins included Endo-B1 (as isoforms: Endo-B1 B/C - neuron specific; Endo-B1 A - ubiquitous), HDAC2 (which regulates Endo-B1), Drp1, Opa1, Mfn2, and Mff (Figure 7). Only EndoB1-B/C (neuronal specific) showed a timerelated change in expression $\left(\mathrm{F}_{(2,11)}=12.47, \mathrm{p}=0.0015\right)$, with post-hoc Dunnett's test demonstrating significant reductions 1 day post-kindling $(\mathrm{p}=0.0057)$. Neither 
hippocampal ubiquitous EndoB1-A expression $\left(\mathrm{F}_{(2,11)}=2.717\right.$, $\left.\mathrm{p}>0.1\right)$ nor HDAC2 $\left(\mathrm{F}_{(2,11)}=\right.$ $0.2972, p>0.7)$ expression were significantly affected with kindling. The expression of several critical regulators of mitochondrial membrane integrity increased in a time-related manner over baseline, including: $\operatorname{Drp} 1\left(\mathrm{~F}_{(2,11)}=17.06, \mathrm{p}=0.0004\right)$; Figure 7D, which also showed significant post-hoc elevation 7 days-post kindling $(\mathrm{p}=0.0007)$; Opa1-L $\left(\mathrm{F}_{(2,11)}=\right.$ 13.36, $\mathrm{p}=0.0011$; Figure 7E), which was found to be significantly elevated 7 days postkindling $(\mathrm{p}=0.008)$; and Opa1-S $(\mathrm{F}(2,11)=10.10, \mathrm{p}=0.0032$; Figure $7 \mathrm{~F})$, which was also significantly elevated 7 days post-kindling $(\mathrm{p}=0.0018)$. Further, the expression of both Mfn2 and Mff, regulators of mitochondrial fusion and fission, respectively, were both elevated $\left(\mathrm{F}(2,11)=16.28, \mathrm{p}=0.0005 ; \mathrm{F}_{(2,11)}=5.384, \mathrm{p}=0.035\right.$, respectively $)$. Mfn2 levels were significantly elevated at both 1 and 7 days post-SE (Figure 7G, $p<0.001$ ); Mff levels were significantly elevated at 7 days post-SE (Figure $7 \mathrm{H}, \mathrm{p}=0.0385$ ). Thus, the corneal kindling process is associated with marked time-related changes in the expression of proteins regulating both mitochondrial fission (Drp1 and Mff) and fusion (Opa1 and Mfn2), indicating a high degree of mitochondrial stress in the early phases of this model of acquired epilepsy.

A

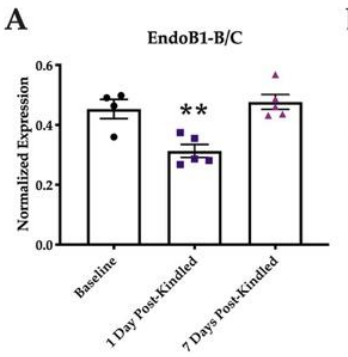

E

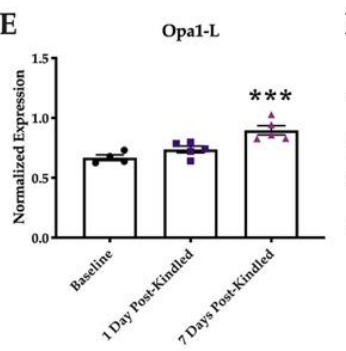

B

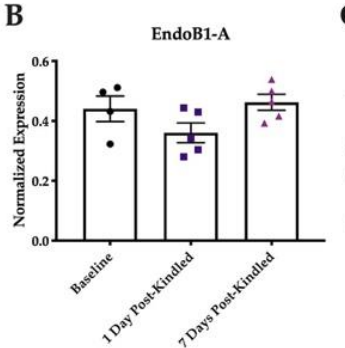

F

亳
C

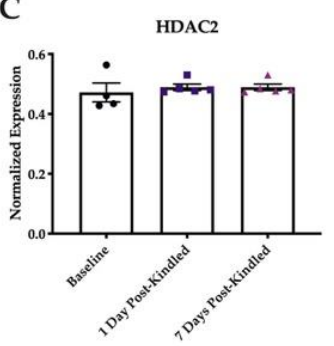

G



$\begin{array}{lllllllllllllll}\text { J2 } & \text { J } & \text { J4 } & \text { J5 } & \text { A5 } & \text { B3 } & \text { B4 } & \text { G1 } & \text { H3 } & \text { B1 } & \text { B2 } & \text { B5 } & \text { E1 } & \text { E3 } & \end{array}$

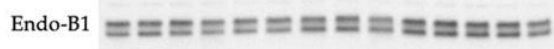
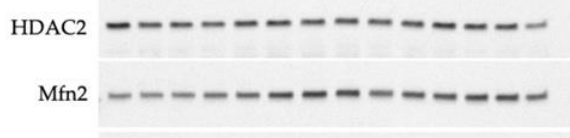

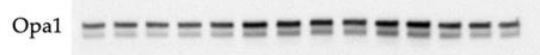

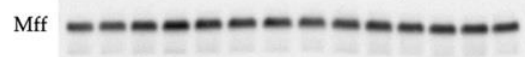

Drp1 -----------

Actin

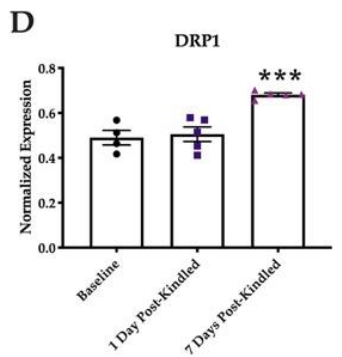

H

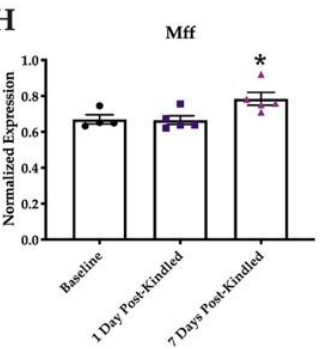

Figure 7. Fully kindled male CF-1 mice demonstrate evidence of dynamic changes in mitochondrial membrane integrity-associated protein expression within isolated hippocampus in a time-related manner. Hippocampal tissues were microdissected prior to kindling acquisition or 1 or 7 days after acquisition of the fully kindled state. A) Expression of the mitochondrial protein EndoB1-B/C isoform was significantly reduced 1 day after acquisition of the fully kindled state, but returned to baseline levels by 7-days post-kindling. B) Expression of the neuron-specific mitochondrial protein EndoB1-A isoform was not significantly reduced by corneal kindling. C) Expression of HDAC2, which modulates EndoB1 expression, was not significantly affected by corneal kindling. D) Expression of Drp-1, a mitochondrial GTPase, was significantly elevated 7 days after acquisition of the fully kindled state. DRP1 recruitment to mitochondria is necessary and 
sufficient for mitochondrial fission in periods of cellular stress. E) Expression of Opa-1 long (Opa1L) and Opa-1 short (Opa1-S) on the inner mitochondrial membrane with mitofusin 2 (Mfn2) on the mitochondrial outer membrane are critical to the maintenance of fusion competent mitochondria under periods of cellular stress. Expression of the Opa1-L isoform was significantly elevated 7 days after acquisition of the fully kindled state. F) Expression of the Opa1-S isoform was significantly elevated 7 days after acquisition of the fully kindled state. G) Expression of mitofusin (Mfn2) was significantly elevated by kindling in general, showing robust increases at both 1-day and 7-days post-kindling acquisition. H) Expression of mitochondrial fission factor (Mff) was significantly elevated 7-days post kindling acquisition. I) All protein bands of interest were normalized against $\beta$-actin values within the same blot. Animal IDs are listed above each corresponding protein lane. All statistical analysis was conducted by one-way ANOVA; ${ }^{*}$ indicates $\mathrm{p}<0.05,{ }^{* *}$ indicates $\mathrm{p}<0.01$, and ${ }^{* * *}$ indicates $\mathrm{p}<0.001$.

\section{Discussion}

This study had two primary objectives: first, to precisely and directly quantify the expression of $\mathrm{H}_{2} \mathrm{~S}$ and its downstream metabolite in whole brain homogenates and purified plasma from acute and chronic seizure models in mice; and second, to define the degree to which mitochondrial membrane integrity-related proteins were dynamically affected with chronic seizures. We herein demonstrate that acute and repeated seizures lead to transient reductions in plasma $\mathrm{H}_{2} \mathrm{~S}$ levels, GSH, and thiocyanate, suggesting that $\mathrm{H}_{2} \mathrm{~S}$ may be a novel biomarker of acute seizures. Further, we quantified the relative expression of mitochondrial membrane integrity-related proteins by western blot in the isolated hippocampus of the corneal kindled mouse model during epileptogenesis and demonstrated time-related increases in the anti-apoptotic protein Opa1, as well as Mff, Mfn2, and Drp1. Given that the corneal kindled mouse model is not defined by neurodegeneration at the time points presently examined [38], this study demonstrates that mitochondrial quality control processes are actively engaged in early kindling, but that these events may sufficiently prevent neurodegeneration despite the development of chronic seizures [38]. Our findings shed critical insight on the role that mitochondrial fission and fusion plays in neuronal apoptosis, and supports future research to address the roles of mitochondrial membrane integrity dynamics in epileptogenesis.

Our study is the first to demonstrate rapid reductions in plasma $\mathrm{H}_{2} \mathrm{~S}$ levels following a single seizure. The mouse MES test is a well-characterized model of generalized tonicclonic seizure and is routinely implemented for drug discovery $[36,41]$. The MES model is substantially differentiated from the pharmacoresistant $6 \mathrm{~Hz} 44 \mathrm{~mA}$ seizure model in its engagement of hippocampal and limbic structures [42], as well as a differentiated pharmacological sensitivity [42-47]. We now demonstrate that the generalized MES test is also substantially differentiated from the $6 \mathrm{~Hz} 44 \mathrm{~mA}$ focal seizure by the changes of plasma $\mathrm{H}_{2} \mathrm{~S}$ levels 1 hour after stimulation. $\mathrm{H}_{2} \mathrm{~S}$ may thus be a uniquely sensitive biomarker of seizure history and type. Moreover, augmentation of $\mathrm{H}_{2} \mathrm{~S}$ may be anticonvulsant: Efron elegantly described in 1956 a case of a patient whose seizures with olfactory auras could be controlled by exposure to strong and unpleasant odors, including $\mathrm{H}_{2} \mathrm{~S}$ [48]. Given that the nasal epithelium is one of the most direct routes of CNS penetrance, further studies of the acute anticonvulsant efficacy of $\mathrm{H}_{2} \mathrm{~S}$ are needed.

One major difficulty in prior studies on the role of $\mathrm{H}_{2} \mathrm{~S}$ was the inability to precisely measure levels of this gasotransmitter in tissues and plasma samples. Our present study provides a major advance to the further quantitative study of $\mathrm{H}_{2} \mathrm{~S}$ in preclinical models of neurological disease, including epilepsy. Despite demonstrating the ability to robustly measure $\mathrm{H}_{2} \mathrm{~S}$ levels via LC-MS/MS in isolated tissue, $\mathrm{H}_{2} \mathrm{~S}$ levels or genes associated with the $\mathrm{H}_{2} \mathrm{~S}$ pathway were not dynamically altered in the corneal kindled mice compared to the sham control group. As it currently stands, it remains unclear whether $\mathrm{H}_{2} \mathrm{~S}$ expression in the hippocampus of mice undergoing corneal kindling is protective or detrimental to the ultimate development of the fully kindled state and the associated reactive astrogliosis [38]. Brain MeSH levels, on the other hand, were significantly lower after five stimulation sessions, though the levels returned to baseline upon full kindling. Similarly, plasma $\mathrm{H}_{2} \mathrm{~S}$ and $\mathrm{MeSH}$ levels were significantly decreased during the initial phases of kindling, but 
were no different from sham by 7 days post-kindling, suggesting the importance of active development of a hyperexcitable neuronal network versus establishment of the fully kindled state. Taken together, this data suggests that the corneal kindling model is not suitable for monitoring dynamic alterations in $\mathrm{H}_{2} \mathrm{~S}$ levels and neurodegeneration may be a prerequisite; however, this is not to dismiss a role for $\mathrm{H}_{2} \mathrm{~S}$ in the onset and progression of epilepsy and mitochondrial membrane integrity dynamics.

Healthy mitochondria are essential to neuronal viability, function, and connectivity. Mitochondria fulfill their diverse functions partly through constant remodeling via fission and fusion. Dysregulation of mitochondrial fission and fusion contributes to numerous types of nervous system disease [29]. Mitochondrial dysfunction contributes to the neurodegeneration in epilepsy, including in animal models [49]. Importantly, the corneal kindling model does not evoke neurodegeneration at the time points examined [38], suggesting that neurodegeneration is necessary to alter $\mathrm{H}_{2} \mathrm{~S}$ levels in early epileptogenesis. Mitochondrial dysfunction may further promote epileptogenesis due to this neurodegeneration. The corneal kindled mouse, like other kindling models, is not characterized by spontaneous recurrent seizures (SRS) at the time points examined in this study, suggesting that hippocampal neurodegeneration both necessary for SRS onset in some models of acquired epilepsy. Indeed, oxidative stress within the hippocampus coincides with the onset of acute seizures and neurodegeneration in a mouse model of infection-induced epilepsy, which is sustained into the period preceding SRS (e.g., the latent period) [50]. Taken together with our present findings, mitochondrial dysfunction contribute to SRS. Our present findings suggest that changes in the neuron-specific isoform of Endo-B1B/C and mitochondrial damage may occur without neuronal loss induced by SRS, or even chronic seizures. Given the absence of neurodegeneration in the corneal kindling model versus other mouse models of acquired epilepsy [38], further work is necessary to precisely interrogate the degree of mitochondrial dysfunction that underlies the development epilepsy.

In the isolated hippocampus of corneal kindled mice, there were significant, timerelated increases in the protein expression of Drp1, Opa1 (short and long isoforms), Mfn2, and Mff at 7 days post-kindling, a time when secondarily generalized seizures are readily evoked in response to the previously benign electrical stimulus [42-47]. Interestingly, the expression of Opa1 mRNA was significantly decreased in isolated hippocampus while Mfn2 mRNA expression was unaltered at 1- and 7-days post-kindling, suggesting differences in post-transcriptional processing. Opa1 is involved in different critical functions underlying mitochondrial membrane integrity, including maintenance of the respiratory chain and membrane potential [51], cristae organization and apoptotic signaling [52,53], and is necessary together with Mfn2 for membrane fusion to preserve dysfunctional mitochondria [54]. Notably, fusion is prevented in dysfunctional mitochondria by proteolytic cleavage of Opa1-L to Opa1-S. The Opa1-mediated process of mitochondrial fusion can be rescued with Opa1 overexpression [52], suggesting that the increase in Opa1 protein presently observed may have been a compensatory response in times of high cellular stress. It should be additionally noted that Opa1 can also signal apoptotic cytochrome $c$ release with the onset of cristae remodeling; a process that is functionally distinct from that which is initiated for mitochondrial fusion. Because the corneal kindling model is not characterized by neurodegeneration, but is associated with extensive astrogliosis at the time points examined [38], our present studies highlight a potential neuroprotective role for Opa1 in chronic seizures.

The role of gasotransmitters, $\mathrm{NO}$ and $\mathrm{H}_{2} \mathrm{~S}$, following episodes of seizures have been previously explored to promote neuroprotection. We demonstrated an increase in Nos2 expression during kindling, which then returned to baseline upon acquisition of the fully kindled state. The present transient changes in $\mathrm{H}_{2} \mathrm{~S}$ levels during the kindling process, coupled with the enhanced levels of Nos2 expression and upregulation of Opa1 isoforms suggests a high likelihood that anti-apoptotic processes may be recruited to mitigate excitotoxicity. Dysfunctional mitochondria can be repaired and rescued by re-fusion to 
the mitochondrial network, which may preserve neuronal integrity and preserve neuronal tissues in this model.

Despite significant advances in our understanding of the role of $\mathrm{H}_{2} \mathrm{~S}$ in the pathophysiology of neurological disease, in general, numerous issues remain unresolved. With these present studies and the application of newly developed quantitative methods to accurately measure $\mathrm{H}_{2} \mathrm{~S}$ and other thiol compound levels from isolated mouse brain, our understanding of the role $\mathrm{H}_{2} \mathrm{~S}$ signaling in the brain, as well as the contributions of mitochondrial integrity dynamics in the pathophysiology of early epilepsy, is advanced. Through future studies with additional preclinical models of epilepsy, including those that are characterized by spontaneous seizures, the therapeutic potential of targeting $\mathrm{H}_{2} \mathrm{~S}$ expression in the brain and regulation of mitochondrial quality control will be better resolved.

\section{Materials and Methods}

Reagents: Water, acetonitrile, and acetic acid are all optima grade from Fisher Scientific. Monobromobimane, MBB, was from Toronto Research Chemicals. Trizma $\mathrm{HCl}$, Trizma Base, diethylenetriaminepentaacetic acid (DETAPAC), ACS reagent grade 5sulfosalicylic acid dihydrate were from Millipore-Sigma.

Animals: All animal experimentation was approved by the University of Washington Institutional Animal Care and Use Committee under approval number 438701 (MBH; approval dates 5/5/2016 and 5/1/2019), University of Washington Public Health Service (PHS) Assurance issued by the Office of Laboratory Animal Welfare (OLAW) assurance number D16-00292, and University of Washington AAALAC accreditation number \#000523. Male CF-1 mice (4-8 weeks; Envigo, Indianapolis, IN, USA) were housed 5 mice/cage in a temperature-controlled vivarium on a 14:10 light/dark cycle. Mice had free access to irradiated chow (Picolab 5053) and water, except during periods of behavioral testing. Mice were allowed a minimum of 4 days habituation to the housing facility, given a minimum of 1 hour to acclimate to the procedure room prior to all experimentation, and euthanized by decapitation at the completion of all in-life studies. Upon euthanasia at the designated time point after stimulation (or sham), the brain was rapidly removed and hippocampus isolated and flash-frozen on dry ice. Brain samples were stored at $-80^{\circ} \mathrm{C}$ until analytical processing. Trunk blood for $\mathrm{H}_{2} \mathrm{~S}$ analysis was collected with Li-Heparin as the anticoagulant. Plasma was isolated by $10 \mathrm{~min}$ centrifugation at $3,000 \times \mathrm{xg}$ at $4^{\circ} \mathrm{C}$ and stored at $-80^{\circ} \mathrm{C}$ until analytical processing.

Maximal electroshock seizure (MES): MES is considered a clinically validated model for generalized tonic-clonic seizures [36]. An alternating current $(60 \mathrm{~Hz}, 50 \mathrm{~mA} ; 0.2$ sec) was delivered bilaterally through corneal electrodes; the eyes of mice were anesthetized with $0.5 \%$ tetracaine $\mathrm{HCl}$ in $0.9 \%$ saline prior to stimulation.

$6 \mathrm{~Hz} 44 \mathrm{~mA}$ seizure model: The $6 \mathrm{~Hz}$ test is considered a model of focal seizures that become generalized [36]. Seizures were induced by a low-frequency stimulus $(6 \mathrm{~Hz}, 3 \mathrm{sec})$ delivered bilaterally to anesthetized corneal electrodes.

Corneal kindled mouse (CKM): For corneal kindling, mice were stimulated with an initially benign electrical current $(60 \mathrm{~Hz}$, sinusoidal pulse; $3.0 \mathrm{~mA}$ ) delivered for $3 \mathrm{sec}$ via corneal electrodes [18-20]. Seizures were scored upon a 5-point rating scale consistent with the Racine scale in amygdala-kindled rats and routinely used by our group for corneal kindled mice,[18-23] wherein; 1 = jaw chomping and vibrissae twitching, 2 = head bobbing and Straub tail, $3=$ unilateral forelimb clonus, $4=$ bilateral forelimb clonus and hind-limb rearing, $5=$ bilateral forelimb clonus and rearing followed by loss of righting reflex. Twice daily stimulations continued for each mouse until it achieved the criterion of 5 consecutive Racine stage 5 seizures, whereby the mouse was considered "fully kindled". Any mouse not achieving the fully kindled state was not included in further study.

Immunoblot: Protein extracts for western blot analysis were prepared as previously reported [27]. Primary antibodies used were: mouse monoclonal Endophilin (Novus; NBP2-24733; 1:500); rabbit polyclonal Mff (Proteintech; 17090-1-AP, 1:2000); rabbit monoclonal Mfn2 (Abcam; ab124773, 1:2000); mouse monoclonal HDAC2 (Sigma; H2663, 
1:5000); mouse monoclonal Opa-1 (clone 18/OPA1, 1: 5000; BD Biosciences); mouse monoclonal Drp1 (clone 8/DLP1, 1:1000; BD Biosciences); and mouse monoclonal $\beta$-actin (clone AC-15, 1:10,000; Sigma-Aldrich), as previously reported [29]. Horseradish peroxidase-conjugated secondary antibodies (1:2000) were from GE Healthcare. For quantification, images were digitally scanned and band intensity measured using NIH ImageJ software [55], and normalized against $\beta$-actin band intensity.

Total RNA isolation and RT-qPCR analysis: The right hemisphere of each brain sample was homogenized in TRI-reagent using the Precellys bead beater $(6800 \mathrm{rpm}$, 3x30 sec cycles, 60 sec delay) followed by extraction using the RNAeasy Lipid Tissue Mini kit (Qiagen, Germantown, MD) to isolate total RNA. RNA purity (A260/280) was assessed, and yield was determined using the Tecan Spark multimode microplate reader (Mannedorf, Switzerland). Total RNA was synthesized to cDNA by reverse transcriptase using the High-Capacity RNA-to-cDNA kit (Thermo Fisher Scientific, Waltham, MA). RTqPCR was then conducted utilizing the Taqman Gene Expression Assays (FAM dye; Thermo Fisher Scientific, Waltham, MA) and gene expression was normalized to the housekeeping gene, Gus-B, following the comparative CT method.

Synthesis of standards for LC-MS/MS: The internal standard, propanethiol bimane, was synthesized by mixing $30 \mathrm{mg}$ of 1-propanethiol with $30 \mathrm{mg}$ of monobromobimane (MBB) in $100 \mathrm{mM} \mathrm{pH} 9.0$ Tris buffer for 1 hour in a $37^{\circ} \mathrm{C}$ water bath. The product was extracted using 3 volumes of ethyl acetate that were pooled and dried under nitrogen gas. The product was then re-dissolved in acetonitrile and purified by column chromatography. The silica gel column was loaded with product and washed with water to remove impurities, then eluted with acetonitrile. This product was dried and redissolved in acetonitrile and its identity verified by high resolution mass spectrometry using an Agilent 6500 Q-TOF. Derivatized hydrogen sulfide and methanethiol standards were prepared similarly.

Sample preparation for LC-MS/MS: All tissue and plasma samples were stored at $80^{\circ} \mathrm{C}$ until use. During the derivatization process, samples were handled on ice under light limited to red LED bulbs. All solvents had oxygen reduced by vacuuming while stirring, followed by sparging with nitrogen gas. This solvent degassing process was performed twice. Samples were handled in a Cleantech glove box (2100-2-A) under nitrogen atmosphere with $>1 \%$ oxygen present until after the derivatization with MBB was complete.

Brain tissues transferred to Precellys $2 \mathrm{~mL}$ reinforced tubes containing $2.8 \mathrm{~mm}$ Qiagen ceramic beads and $1 \mathrm{~mL}$ of $\mathrm{pH} 9.0$ tris $\mathrm{H}_{2} \mathrm{~S}$ trapping buffer with $0.25 \mathrm{mM}$ DETAPAC. They were homogenized in Precellys- 24 cooled by a Cryolys for 3 cycles, 30 seconds each, at $6500 \mathrm{RPM}$. The homogenate was then centrifuged at $10,000 \times \mathrm{g}, 4^{\circ} \mathrm{C}$, for 10 minutes. In a 96-well plate, $30 \mu \mathrm{L}$ of the tissue supernatant or plasma was combined with $30 \mu \mathrm{L}$ of trapping buffer, along with $10 \mu \mathrm{L}$ of $10 \mu \mathrm{M}$ propanethiol bimane internal standard. Then, $25 \mu \mathrm{L}$ of a $20 \mathrm{mM}$ MBB acetonitrile solution was added. The 96-well plate was then sealed with a cap mat and derivatization took place in a $37^{\circ} \mathrm{C}$ water bath for 30 minutes. The reaction was quenched by adding $75 \mu \mathrm{L}$ of $100 \mathrm{mM}$ 5-sulfosalicylic acid. The samples were centrifuged at $4,000 \times \mathrm{g}, 4^{\circ} \mathrm{C}$, for 15 minutes and then the supernatant was transferred to a fresh 96-well plate and analyzed by LC-MS/MS.

LC-MS/MS: $\mathrm{H}_{2} \mathrm{~S}, \mathrm{MeSH}$, etc. were measured using a Waters Xevo TQ-s ESI mass spectrometer operating in positive ion mode coupled to a Waters Acquity I-class UPLC. The chromatography column used was a Waters Acquity UPLC BEH shield C18 column $(1.7 \mu \mathrm{m}, 2.1 \times 150 \mathrm{~mm})$. There was a $10 \mu \mathrm{L}$ injection volume, $0.3 \mathrm{~mL} / \mathrm{minute}$ flow rate, with the column heated to $50^{\circ} \mathrm{C}$. The mobile phases (A) water with $0.2 \%$ acetic acid and (B) acetonitrile with $0.2 \%$ acetic acid. The LC method was 8 minutes long, starting with $99 \%$ $\mathrm{A}$ and ramped down to $60 \% \mathrm{~A}$ at 1.5 minutes, 30\% at 4 minutes, and back to $99 \% \mathrm{~A}$ at 6 minutes. The quadrupole MS was run in SRM positive ion mode with the highest intensity mass transitions chosen for each compound. The capillary voltage was set to $2 \mathrm{kV}$, cone voltage was set to $40 \mathrm{~V}$, with a source offset of $60 \mathrm{~V}$ and a desolvation temperature of $350^{\circ} \mathrm{C}$. 
Calibration curve: Standards for $\mathrm{H}_{2} \mathrm{~S}$ and $\mathrm{MeSH}$ were prepared as stated above. A 5point calibration curve and 3 quality control standards were added to every plate and were spiked into $30 \mu \mathrm{L}$ of a homogeneous plasma pool. The concentrations are given in the table below. Calibration curves for both $\mathrm{H} 2 \mathrm{~S}$ and $\mathrm{MeSH}$ produced $\mathrm{r}^{2}$ values greater than 0.99 and fell within the accepted limits of the FDA bioanalytical method validation [24].

Statistics: Statistical differences in gene expression, protein, and $\mathrm{H}_{2} \mathrm{~S}$ levels were assessed by one-way ANOVA, with Dunnett's post-hoc tests. Kindling acquisition rates between experimental cohorts were compared by Friedman test, a non-parametric test of variance with repeated measures, with Dunn's multiple comparisons post-hoc tests. Percent of fully kindled mice were compared by repeated measures ANOVA, with Dunnett's post-hoc tests. The total numbers of stimulations needed to attain the fully kindled state between the two fully kindled cohorts were compared by t-test. For all statistical measures, $\mathrm{p}<0.05$ was considered significant and all analysis was performed with Prism version 8.0 or later (GraphPad, San Diego, CA, USA).

\begin{abstract}
Author Contributions: Conceptualization, Christi Cho, Maxwell Zeigler, Richard Morrison, Rheem Totah and Melissa Barker-Haliski; Formal analysis, Christi Cho, Maxwell Zeigler, Rheem Totah and Melissa Barker-Haliski; Funding acquisition, Melissa Barker-Haliski; Investigation, Christi Cho, Maxwell Zeigler, Stephanie Mizuno, Richard Morrison, Rheem Totah and Melissa Barker-Haliski; Methodology, Christi Cho, Maxwell Zeigler, Rheem Totah and Melissa Barker-Haliski; Resources, Rheem Totah and Melissa Barker-Haliski; Supervision, and Melissa Barker-Haliski; Writing original draft, Christi Cho, Maxwell Zeigler, Stephanie Mizuno, Rheem Totah and Melissa BarkerHaliski; Writing - review \& editing, Christi Cho, Maxwell Zeigler, Rheem Totah and Melissa BarkerHaliski.
\end{abstract}

Funding: This research was supported by unrestricted funds from the University of Washington Department of Pharmacy, an NCATS/ITHS KL2 award to MBH (KL2TR002317). The APC was funded by unrestricted funds from the University of Washington Department of Pharmacy to MBH.

Institutional Review Board Statement: No human subjects were used in these studies.

Data Availability Statement: Data is contained within the article. For additional requests please contact the corresponding author.

Acknowledgements: We wish to gratefully acknowledge the scientific input and intellectual contributions of our colleague, Richard S. Morrison, PhD, who passed away during the completion of the studies for this manuscript. He was a good friend and mentor. The authors acknowledge the manuscript draft review assistance of Michelle Guignet, $\mathrm{PhD}$ and Jessica Young, $\mathrm{PhD}$. The authors wish to acknowledge the technical assistance of Mr. Zachery Koneval, Ms. Dannielle Zierath, and Ms. Chizuru Kinoshita.

Conflicts of Interest: The authors declare no conflict of interest. The funders had no role in the design of the study; in the collection, analyses, or interpretation of data; in the writing of the manuscript, or in the decision to publish the results.

\title{
References
}

1. Puttachary, S.; Sharma, S.; Stark, S.; Thippeswamy, T. Seizure-induced oxidative stress in temporal lobe epilepsy. Biomed Res Int 2015, 2015, 745613, doi:10.1155/2015/745613.

2. Kannan, K.; Jain, S.K. Oxidative stress and apoptosis. Pathophysiology 2000, 7, 153-163.

3. Li, L.; Rose, P.; Moore, P.K. Hydrogen sulfide and cell signaling. Annu Rev Pharmacol Toxico/ 2011, 51, 169-187, doi:10.1146/annurev-pharmtox-010510-100505.

4. Paul, B.D.; Snyder, S.H. H(2)S signalling through protein sulfhydration and beyond. Nat Rev Mol Cell Bio/2012, 13, 499-507, doi:10.1038/nrm3391.

5. Zhang, X.; Bian, J.S. Hydrogen sulfide: a neuromodulator and neuroprotectant in the central nervous system. $A C S$ Chem Neurosci 2014, 5, 876-883, doi:10.1021/cn500185g.

6. Zhang, Y.; Li, K.; Wang, X.; Ding, Y.; Ren, Z.; Fang, J.; Sun, T.; Guo, Y.; Chen, Z.; Wen, J. CSE-Derived H2S Inhibits Reactive Astrocytes Proliferation and Promotes Neural Functional Recovery after Cerebral Ischemia/Reperfusion 
Injury in Mice Via Inhibition of RhoA/ROCK2 Pathway. ACS Chem Neurosci 2021, 12, 2580-2590, doi:10.1021/acschemneuro.0c00674.

7. Kimura, Y.; Kimura, H. Hydrogen sulfide protects neurons from oxidative stress. FASEB J 2004, 18, 1165-1167, doi:10.1096/fj.04-1815fje.

8. Kimura, Y.; Goto, Y.; Kimura, H. Hydrogen sulfide increases glutathione production and suppresses oxidative stress in mitochondria. Antioxid Redox Signa/2010, 12, 1-13, doi:10.1089/ars.2008.2282.

9. Tabassum, R.; Jeong, N.Y. Potential for therapeutic use of hydrogen sulfide in oxidative stress-induced neurodegenerative diseases. Int J Med Sci 2019, 16, 1386-1396, doi:10.7150/ijms.36516.

10. Murphy, B.; Bhattacharya, R.; Mukherjee, P. Hydrogen sulfide signaling in mitochondria and disease. FASEB J 2019, 33, 13098-13125, doi:10.1096/fj.201901304R.

11. Sbodio, J.I.; Snyder, S.H.; Paul, B.D. Regulators of the transsulfuration pathway. Br J Pharmaco/2019, 176, 583593, doi:10.1111/bph.14446.

12. Kohl, J.B.; Mellis, A.T.; Schwarz, G. Homeostatic impact of sulfite and hydrogen sulfide on cysteine catabolism. $\mathrm{Br}$ J Pharmaco/2019, 176, 554-570, doi:10.1111/bph.14464.

13. Szabo, C. Hydrogen Sulfide, an Endogenous Stimulator of Mitochondrial Function in Cancer Cells. Cells 2021, 10, doi:10.3390/cells10020220.

14. Fu, M.; Zhang, W.; Wu, L.; Yang, G.; Li, H.; Wang, R. Hydrogen sulfide (H2S) metabolism in mitochondria and its regulatory role in energy production. Proc Natl Acad Sci U S A 2012, 109, 2943-2948, doi:10.1073/pnas.1115634109.

15. Abe, K.; Kimura, H. The possible role of hydrogen sulfide as an endogenous neuromodulator. The Journal of neuroscience : the official journal of the Society for Neuroscience 1996, 16, 1066-1071.

16. Kimura, H. Hydrogen sulfide as a neuromodulator. Mol Neurobio/2002, 26, 13-19, doi:10.1385/MN:26:1:013.

17. Zhang, F.; Chen, S.; Wen, J.Y.; Chen, Z.W. 3-Mercaptopyruvate sulfurtransferase/hydrogen sulfide protects cerebral endothelial cells against oxygen-glucose deprivation/reoxygenation-induced injury via mitoprotection and inhibition of the RhoA/ROCK pathway. Am J Physiol Cell Physiol 2020, 319, C720-C733, doi:10.1152/ajpcell.00014.2020.

18. Frasdorf, B.; Radon, C.; Leimkuhler, S. Characterization and interaction studies of two isoforms of the dual localized 3-mercaptopyruvate sulfurtransferase TUM1 from humans. The Journal of biological chemistry 2014, 289, 34543-34556, doi:10.1074/jbc.M114.605733.

19. Yang, J.; Minkler, P.; Grove, D.; Wang, R.; Willard, B.; Dweik, R.; Hine, C. Non-enzymatic hydrogen sulfide production from cysteine in blood is catalyzed by iron and vitamin B6. Commun Biol 2019, 2, 194, doi:10.1038/s42003-019-0431-5.

20. Pearson-Smith, J.N.; Patel, M. Metabolic Dysfunction and Oxidative Stress in Epilepsy. Int J Mo/ Sci 2017, 18, doi:10.3390/ijms18112365.

21. Pearson-Smith, J.N.; Liang, L.P.; Rowley, S.D.; Day, B.J.; Patel, M. Oxidative Stress Contributes to Status Epilepticus Associated Mortality. Neurochemical research 2017, 42, 2024-2032, doi:10.1007/s11064-017-2273-1.

22. Johri, A.; Beal, M.F. Mitochondrial dysfunction in neurodegenerative diseases. The Journal of pharmacology and experimental therapeutics 2012, 342, 619-630, doi:10.1124/jpet.112.192138.

23. Reddy, P.H.; Reddy, T.P.; Manczak, M.; Calkins, M.J.; Shirendeb, U.; Mao, P. Dynamin-related protein 1 and mitochondrial fragmentation in neurodegenerative diseases. Brain Res Rev 2011, 67, 103-118, doi:10.1016/j.brainresrev.2010.11.004.

24. Qiu, X.; Cao, L.; Yang, X.; Zhao, X.; Liu, X.; Han, Y.; Xue, Y.; Jiang, H.; Chi, Z. Role of mitochondrial fission in neuronal injury in pilocarpine-induced epileptic rats. Neuroscience 2013, 245, 157-165, doi:10.1016/j.neuroscience.2013.04.019.

25. Cuddeback, S.M.; Yamaguchi, H.; Komatsu, K.; Miyashita, T.; Yamada, M.; Wu, C.; Singh, S.; Wang, H.G. Molecular cloning and characterization of Bif-1. A novel Src homology 3 domain-containing protein that associates with Bax. The Journal of biological chemistry 2001, 276, 20559-20565, doi:10.1074/jbc.M101527200.

26. Wang, D.B.; Kinoshita, Y.; Kinoshita, C.; Uo, T.; Sopher, B.L.; Cudaback, E.; Keene, C.D.; Bilousova, T.; Gylys, K.; Case, A.; et al. Loss of endophilin-B1 exacerbates Alzheimer's disease pathology. Brain : a journal of neurology 2015, 138, 2005-2019, doi:10.1093/brain/awv128.

27. Wang, D.B.; Uo, T.; Kinoshita, C.; Sopher, B.L.; Lee, R.J.; Murphy, S.P.; Kinoshita, Y.; Garden, G.A.; Wang, H.G.; Morrison, R.S. Bax interacting factor-1 promotes survival and mitochondrial elongation in neurons. The Journal 
of neuroscience : the official journal of the Society for Neuroscience 2014, 34, 2674-2683, doi:10.1523/JNEUROSCI.4074-13.2014.

28. Cheung, Z.H.; Ip, N.Y. Endophilin B1: Guarding the gate to destruction. Commun Integr Bio/ 2009, 2, 130-132, doi:10.4161/cib.7745.

29. Frankowski, H.; Yeboah, F.; Berry, B.J.; Kinoshita, C.; Lee, M.; Evitts, K.; Davis, J.; Kinoshita, Y.; Morrison, R.S.; Young, J.E. Knock-Down of HDAC2 in Human Induced Pluripotent Stem Cell Derived Neurons Improves Neuronal Mitochondrial Dynamics, Neuronal Maturation and Reduces Amyloid Beta Peptides. Int J Mol Sci 2021, 22, doi:10.3390/ijms22052526.

30. Li, H.; Alavian, K.N.; Lazrove, E.; Mehta, N.; Jones, A.; Zhang, P.; Licznerski, P.; Graham, M.; Uo, T.; Guo, J.; et al. A $\mathrm{Bcl}-\mathrm{xL}$-Drp1 complex regulates synaptic vesicle membrane dynamics during endocytosis. Nat Cel/ Bio/2013, 15, 773-785, doi:10.1038/ncb2791.

31. Elrod, J.W.; Calvert, J.W.; Morrison, J.; Doeller, J.E.; Kraus, D.W.; Tao, L.; Jiao, X.; Scalia, R.; Kiss, L.; Szabo, C.; et al. Hydrogen sulfide attenuates myocardial ischemia-reperfusion injury by preservation of mitochondrial function. Proc Natl Acad Sci U S A 2007, 104, 15560-15565, doi:10.1073/pnas.0705891104.

32. Qiao, P.; Zhao, F.; Liu, M.; Gao, D.; Zhang, H.; Yan, Y. Hydrogen sulfide inhibits mitochondrial fission in neuroblastoma N2a cells through the Drp1/ERK1/2 signaling pathway. Mol Med Rep 2017, 16, 971-977, doi:10.3892/mmr.2017.6627.

33. de Moura Alvorcem, L.; Britto, R.; Parmeggiani, B.; Glanzel, N.M.; da Rosa-Junior, N.T.; Cecatto, C.; Bobermin, L.D.; Amaral, A.U.; Wajner, M.; Leipnitz, G. Evidence that thiol group modification and reactive oxygen species are involved in hydrogen sulfide-induced mitochondrial permeability transition pore opening in rat cerebellum. Mitochondrion 2019, 47, 141-150, doi:10.1016/j.mito.2018.11.001.

34. Zhao, Y.; Biggs, T.D.; Xian, M. Hydrogen sulfide (H2S) releasing agents: chemistry and biological applications. Chem Commun (Camb) 2014, 50, 11788-11805, doi:10.1039/c4cc00968a.

35. Ahmed, M.A.; Kamel, E.O. Involvement of H2 S, NO and BDNF-TrkB signalling pathway in the protective effects of simvastatin against pentylenetetrazole-induced kindling and cognitive impairments in mice. Basic Clin Pharmacol Toxicol2020, 127, 461-476, doi:10.1111/bcpt.13457.

36. Barker-Haliski, M.; White, H.S. Validated animal models for antiseizure drug (ASD) discovery: Advantages and potential pitfalls in ASD screening. Neuropharmacology 2019, 107750, doi:10.1016/j.neuropharm.2019.107750.

37. Sutula, T.P.; Kotloski, R.J. Kindling: A Model and Phenomenon of Epilepsy. In Models of Seizure and Epilepsy, 2nd ed.; Pitkanen, A., Buckmaster, P.S., Galanopoulou, A.S., Moshe, S.L., Eds.; Academic Press: 2017; pp. $813-825$.

38. Loewen, J.L.; Barker-Haliski, M.L.; Dahle, E.J.; White, H.S.; Wilcox, K.S. Neuronal Injury, Gliosis, and Glial Proliferation in Two Models of Temporal Lobe Epilepsy. Journal of neuropathology and experimental neurology 2016, 75, 366-378, doi:10.1093/jnen/nlw008.

39. Maldonato, B.J.; Russell, D.A.; Totah, R.A. Human METTL7B is an alkyl thiol methyltransferase that metabolizes hydrogen sulfide and captopril. Sci Rep 2021, 11, 4857, doi:10.1038/s41598-021-84218-5.

40. Nagahara, N.; Ito, T.; Minami, M. Mercaptopyruvate sulfurtransferase as a defense against cyanide toxication: molecular properties and mode of detoxification. Histology and histopathology 1999, 14, 1277-1286, doi:10.14670/HH-14.1277.

41. Barker-Haliski, M. How do we choose the appropriate animal model for antiseizure therapy development? Expert Opin Drug Discov 2019, 1-5, doi:10.1080/17460441.2019.1636782.

42. Barton, M.E.; Klein, B.D.; Wolf, H.H.; White, H.S. Pharmacological characterization of the $6 \mathrm{~Hz}$ psychomotor seizure model of partial epilepsy. Epilepsy research 2001, 47, 217-227.

43. Metcalf, C.S.; West, P.J.; Thomson, K.E.; Edwards, S.F.; Smith, M.D.; White, H.S.; Wilcox, K.S. Development and pharmacologic characterization of the rat $6 \mathrm{~Hz}$ model of partial seizures. Epilepsia 2017, 58, 1073-1084, doi:10.1111/epi.13764.

44. Barker-Haliski, M.L.; Johnson, K.; Billingsley, P.; Huff, J.; Handy, L.J.; Khaleel, R.; Lu, Z.; Mau, M.J.; Pruess, T.H.; Rueda, C.; et al. Validation of a Preclinical Drug Screening Platform for Pharmacoresistant Epilepsy. Neurochemical research 2017, 42, 1904-1918, doi:10.1007/s11064-017-2227-7.

45. Leclercq, K.; Kaminski, R.M. Genetic background of mice strongly influences treatment resistance in the $6 \mathrm{~Hz}$ seizure model. Epilepsia 2015, 56, 310-318, doi:10.1111/epi.12893.

46. Walrave, L.; Maes, K.; Coppens, J.; Bentea, E.; Van Eeckhaut, A.; Massie, A.; Van Liefferinge, J.; Smolders, I. Validation of the $6 \mathrm{~Hz}$ refractory seizure mouse model for intracerebroventricularly administered compounds. Epilepsy research 2015, 115, 67-72, doi:10.1016/j.eplepsyres.2015.06.003. 
47. Koneval, Z.; Knox, K.M.; Memon, A.; Zierath, D.K.; White, H.S.; Barker-Haliski, M. Antiseizure drug efficacy and tolerability in established and novel drug discovery seizure models in outbred versus inbred mice. Epilepsia 2020, In press.

48. Efron, R. The effect of olfactory stimuli in arresting uncinate fits. Brain : a journal of neurology 1956, 79, 267-281, doi:10.1093/brain/79.2.267.

49. Fulton, R.E.; Pearson-Smith, J.N.; Huynh, C.Q.; Fabisiak, T.; Liang, L.P.; Aivazidis, S.; High, B.A.; Buscaglia, G.; Corrigan, T.; Valdez, R.; et al. Neuron-specific mitochondrial oxidative stress results in epilepsy, glucose dysregulation and a striking astrocyte response. Neurobiology of disease 2021, 158, 105470, doi:10.1016/j.nbd.2021.105470.

50. Bhuyan, P.; Patel, D.C.; Wilcox, K.S.; Patel, M. Oxidative stress in murine Theiler's virus-induced temporal lobe epilepsy. Experimental neurology 2015, 271, 329-334, doi:10.1016/j.expneurol.2015.06.012.

51. Olichon, A.; Baricault, L.; Gas, N.; Guillou, E.; Valette, A.; Belenguer, P.; Lenaers, G. Loss of OPA1 perturbates the mitochondrial inner membrane structure and integrity, leading to cytochrome $c$ release and apoptosis. The Journal of biological chemistry 2003, 278, 7743-7746, doi:10.1074/jbc.C200677200.

52. Frezza, C.; Cipolat, S.; Martins de Brito, O.; Micaroni, M.; Beznoussenko, G.V.; Rudka, T.; Bartoli, D.; Polishuck, R.S.; Danial, N.N.; De Strooper, B.; et al. OPA1 controls apoptotic cristae remodeling independently from mitochondrial fusion. Cel/2006, 126, 177-189, doi:10.1016/j.cell.2006.06.025.

53. Cipolat, S.; Rudka, T.; Hartmann, D.; Costa, V.; Serneels, L.; Craessaerts, K.; Metzger, K.; Frezza, C.; Annaert, W.; D'Adamio, L.; et al. Mitochondrial rhomboid PARL regulates cytochrome c release during apoptosis via OPA1dependent cristae remodeling. Cel/2006, 126, 163-175, doi:10.1016/j.cell.2006.06.021.

54. Alavi, M.V.; Fuhrmann, N. Dominant optic atrophy, OPA1, and mitochondrial quality control: understanding mitochondrial network dynamics. Mol Neurodegener 2013, 8, 32, doi:10.1186/1750-1326-8-32.

55. Nadanaciva, S.; Willis, J.H.; Barker, M.L.; Gharaibeh, D.; Capaldi, R.A.; Marusich, M.F.; Will, Y. Lateral-flow immunoassay for detecting drug-induced inhibition of mitochondrial DNA replication and mtDNA-encoded protein synthesis. J Immunol Methods 2009, 343, 1-12, doi:10.1016/j.jim.2008.12.002. 